\title{
Entomologia para escoteiros: uma experiência de extensáo do grupo PET Biologia/Uberlândia em diferentes espaços educativos
}

\author{
Entomology for scouts: an extension experience of PET BiologyUberlandia \\ group in different educational spaces
}

\section{RESUMO}

Historicamente o escotismo está atrelado à vida de seu fundador, Robert Stephenson Smyth Baden-Powell, que elaborou a metodologia de sobrevivência e agrupamento, pautada na compreensão da natureza. Destarte, o ensino de entomologia se tornou uma maneira de alcançar os praticantes do escotismo, pelo fato dos insetos serem animais presentes em vários ecossistemas, além de partilharem diversos aspectos da vida do homem. Buscando desenvolver uma atividade em uma realidade diferenciada de ensino-aprendizagem, seguindo a vertente da metodologia de educação não formal, o grupo PET/ Biologia da Universidade Federal de Uberlândia objetivou contribuir com a formação dos escoteiros e, simultaneamente, aprimorar as habilidades dos próprios membros do grupo, utilizando a temática entomologia. Para tal, o trabalho foi realizado com o grupo "Escoteiro Triângulo" entre agosto e novembro de 2014, no município de Uberlândia, perfazendo um total de quatro encontros que, em termos gerais, abordaram respectivamente: aspectos gerais da entomologia, diversidade morfológica dos insetos, patologias causadas por insetos e transmissão de algumas doenças e seus vetores. Os resultados do projeto evidenciaram que a troca de experiência com esse público fez manifestar nos proponentes: maior compreensão da importância do planejamento para executar atividades, transposição do conteúdo, adequação da linguagem, assim como, aplicação de ferramentas estudadas no ensino superior. Tais resultados demonstram que o princípio extensionista deu-se de forma satisfatória.

Palavras-chave: Escoteiros. Extensão. Entomologia. Educação não formal.

\section{ABSTRACT}

Historically, scouting is intimately tied to the life of its founder, Robert Stephenson Smyth Baden-Powell, who developed the methodology
Camilla Cristina Teles Marra

Graduanda em Ciências Biológicas na Universidade Federal de Uberlândia, Minas Gerais, Brasil (camillamarra@ outlook.com).

Letícia Benavalli

Graduanda em Ciências Biológicas na Universidade Federal de Uberlândia, Minas Gerais, Brasil; bolsista de iniciação científica pela Fundação de Amparo à Pesquisa de Minas Gerais (FAPEMIG) (lebenavalli@gmail.com).

Youry Souza Marques

Graduando em Ciências Biológicas na Universidade Federal de Uberlândia, Minas Gerais, Brasil; bolsista de extensão pelo Programa de Extensáo Integração UFU-Comunidade (PEIC 2018) (yurysmsm@gmail.com).

Giuliano Buzá Jacobucci

Doutor em Ecologia pela Universidade Estadual de Campinas, São Paulo, Brasil; professor associado III no Instituto de Biologia da Universidade Federal de Uberlândia, Minas Gerais, Brasil (gbjacobucci@gmail.com). 
of survival and grouping, based on the understanding of nature. Thus, the teaching of entomology would become a way to reach the practitioners of scouting, because the insects are animals present in several ecosystems, in addition to sharing several aspects of human life. In order to develop an activity in a differentiated reality of teaching and learning, following the non-formal education methodology, the PET/Biology Group, Federal Univeristy of Uberlândia, aimed to contribute to the formation of the Boy Scouts and, simultaneously, to improve the abilities of members of the group themselves, using the theme entomology. To do this, the work was carried out with the group "Escoteiro Triângulo" between August and November of 2014, in the city of Uberlândia, with a total of four encounters, in general terms: general aspects of entomology, morphological diversity of insects, pathologies caused by insects and transmission of some diseases and their vectors. The results of the project showed that the exchange of experience with the target audience showed the following: greater understanding of the importance of planning to carry out activities, content transposition, language adequacy, and application of tools studied in higher education. These results show that the extension principle was satisfactory.

Keywords: Scouts. Extension. Entomology. Non-formal education.

\section{INTRODUÇÃO}

\section{Histórico do escotismo}

O movimento escoteiro teve início em 1907, na Inglaterra, e foi idealizado pelo militar Robert Stephenson Smyth Baden-Powell (NASCIMENTO, 2004). A iniciativa teve e, ainda tem, como objetivo: incentivar o jovem em seu crescimento e desenvolvimento por meio de práticas ao ar livre, atividades em equipe e, principalmente, um sistema de valores que priorizam a honra, lealdade, respeito e disciplina. Baden-Powell se baseou nesses valores com o intuito de facilitar o processo de aprender como se portar diante da sociedade, sempre buscando o respeito para com o próximo. Porém, segundo Jorge Carvalho do Nascimento, importante intelectual do escotismo, impor regras vai contra os princípios do movimento, uma vez que esses valores têm a pretensão de despertar o esforço pessoal e a disciplina 
interior (NUNES; FREITAS; GRAÇA, 2011).

O escotismo é marcado por símbolos tanto estéticos quanto comportamentais além de possuir uma organização etária que determina a qual grupo o integrante pertence. No Brasil, ocorre uma divisão em: i) Lobinhos: de 6,5 a 10 anos; ii) Escoteiros: de 11 a 14 anos; iii) Seniores: de 15 a 17 anos; e iv) Pioneiros ou Pioneiras: de 18 a 21 anos (NUNES; FREITAS; GRAÇA, 2011). Em 1909, formouse o primeiro grupo de mulheres, as bandeirantes. Elas faziam parte de um programa semelhante ao dos escoteiros que tinha o mesmo objetivo e código, mas com a diferença de que visavam prestar serviços ao próximo e ter lealdade à pátria. Esse movimento sempre esteve diretamente associado com o escotismo, porque posteriormente foi coordenado pela irmã de Baden-Powell, chamada Agnes (NUNES; FREITAS; GRAÇA, 2011).

O movimento dos escoteiros brasileiro surgiu em 1910, no Rio de Janeiro, com a divulgação de uma carta escrita pelos seus fundadores. Já a Associação Brasileira de Escotismo (ABE) foi criada em São Paulo, em 1914, e foi crucial para a dispersão do movimento nos estados brasileiros. Juntamente com a propagaçáo do escotismo, surgiu um debate acerca das influências e consequências dessa prática na escola (NUNES; FREITAS; GRAÇA, 2011). Acredita-se que esse movimento é um mediador para a prática de ensino não formal (PEREIRA, 2004; FERREIRA; DEUS; SOARES, 2015), devido às circunstâncias sob as quais as atividades são executadas, incluindo a perspectiva de coletividade, o uso do ambiente natural como espaço de construção de saberes com senso comunitário, além de ter como objetivo a consolidação da cidadania (GOHN, 2006).

Além disso, com o objetivo de oferecer uma ampla qualidade de formaçáo pessoal e para a vida, os escoteiros podem conquistar especialidades. Segundo a União dos Escoteiros do Brasil (ESCOTEIROS DO BRASIL, 2017), as especialidades auxiliam no desenvolvimento de novas habilidades em torno de um ponto específico, além de potencializar a exploração de novos interesses. Dessa forma, elas são distribuídas em cinco ramos do conhecimento: serviços, habilidades escoteiras, ciência e tecnologia, desportos e cultura (FERREIRA; DEUS; SOARES, 2015). 


\section{Programa de Educação Tutorial: contexto na Universidade Federal de Uberlândia}

Atividades de extensão constituem um dos pilares de atuação do Programa de Educação Tutorial (PET). O PET é constituído por grupos de alunos de graduaçáo, cujas atividades são orientadas pelo princípio da indissociabilidade entre ensino, pesquisa e extensão (FORPROEX, 2012). Esses grupos são organizados por meio de uma proposta de aprendizagem que busca propiciar aos alunos, sob a orientação de um professor tutor, condiçôes para a realização de atividades extracurriculares, que complementem a sua formação acadêmica, visando atender mais plenamente às necessidades do próprio curso de graduaçáo, ampliando e aprofundando o percurso de sua formaçáo profissional (UFU, 2015, p. 1).

Na Universidade Federal de Uberlândia (UFU) há 30 grupos PET vinculados a diferentes cursos e que desenvolvem atividades muito diversificadas. O grupo PET Biologia/Uberlândia, vinculado aos cursos de Licenciatura e Bacharelado em Ciências Biológicas, atua há 26 anos e já desenvolveu inúmeras propostas de extensão, incluindo iniciativas realizadas em espaços não formais de educação.

A partir de informaçóes de um ex-petiano do PET Biologia, que era líder escoteiro, o grupo manteve um contato inicial com escoteiros de Uberlândia e soube de seu interesse em desenvolver uma proposta que atendesse à especialidade Entomologia (Anexo I). Na perspectiva de aprofundar esse contato, ampliar os conhecimentos dos petianos em biologia de insetos e contribuir para a formaçáo dos escoteiros, o PET Biologia propôs um projeto de extensáo a ser desenvolvido no segundo semestre de 2014.

\section{Especialidade entomologia para escoteiros}

A maior parte das tarefas vivenciadas pelos escoteiros ocorre ao ar livre, por isso o conhecimento a respeito do ambiente natural se faz indispensável. O contato com animais pode ser uma oportunidade de compreender a sua diversidade sob vários aspectos, principalmente sua importância em várias atividades humanas. Como o contato com insetos é ativo, uma vez que esse grupo ocorre em grande 
diversidade de ambientes, se torna necessário o conhecimento sobre sua diversidade (PEREIRA, 2004).

Os insetos constituem um grupo com vasta diversidade, elevada abundância e uma infinidade de relaçóes ecológicas, inclusive com o homem (RAFAEL et al., 2012). Assim, é indispensável conhecêlos e diferenciá-los de outros artrópodes, como os aracnídeos, além de aprender sobre sua importância ecológica, econômica, médica e principais características desse grupo. Por isso, o Movimento Escoteiro possui uma especialidade técnica relacionada à Entomologia que detalha quais aprendizados são essenciais nesse campo de estudo (Anexo I).

Entretanto, apesar de sua importância ecológica, abordar temas relacionados aos insetos com a sociedade é um desafio, visto que esse grupo é negligenciado ou visto como prejudicial por grande parte da população (BRAGA; ARAÚJO; CID, 2012). Uma alternativa de abordagem que pode sensibilizar o público para esses organismos é a realização de atividades educativas em espaços distintos da sala de aula.

Atividades de caráter prático realizadas em praças, parques e laboratórios, por exemplo, facilitam o contato com diferentes grupos de organismos e o desenvolvimento de estratégias didáticas diferenciadas (KRASILCHIK, 2008). A utilização desses espaços pode representar uma importante vertente de propostas extensionistas de muitas universidades, pois permite maior aproximação entre os acadêmicos e a sociedade. Esses momentos são essenciais à democratização dos conhecimentos gerados pela academia e enriquecem a utilização dos espaços públicos (MENDONÇA; SILVA, 2002).

\section{OBJETIVOS}

O objetivo do projeto foi contribuir com a formação de um grupo de escoteiros, desenvolvendo atividades relacionadas à Entomologia e, simultaneamente, aprimorar as habilidades dos próprios membros do grupo PET Biologia/Uberlândia em relação a essa temática. 


\section{DESENVOLVIMENTO}

Em Uberlândia, há três grupos registrados no site da União dos Escoteiros do Brasil - Minas Gerais (UEB-MG): 049 G. E. Potiguar, $056^{\circ}$ G. E. São Sebastião e $132^{\circ}$ G. E. Triângulo. A atividade "Especialidade entomologia para escoteiros" foi realizada com o G. E. Triângulo, com um grupo de 15 escoteiros equivalente aos seniores, no qual um dos petianos já era chefe escoteiro e viu na realização da atividade uma oportunidade de compartilhamento de conhecimentos e vivências entre o PET e os escoteiros. O projeto foi desenvolvido entre agosto e novembro de 2014 e o cronograma incluiu quatro encontros mensais.

O primeiro encontro aconteceu na sede dos escoteiros no Parque Municipal do Sabiá, Uberlândia-MG, tendo sido ministrada uma aula expositivo-dialogada, na qual foram abordados aspectos gerais da Entomologia, assim como a morfologia que diferencia insetos de aracnídeos (Figura 1). A importância médica e os primeiros socorros em casos de acidentes com insetos também foram abordados.

Figura 1 - Aula teórica expositiva no Parque do Sabiá

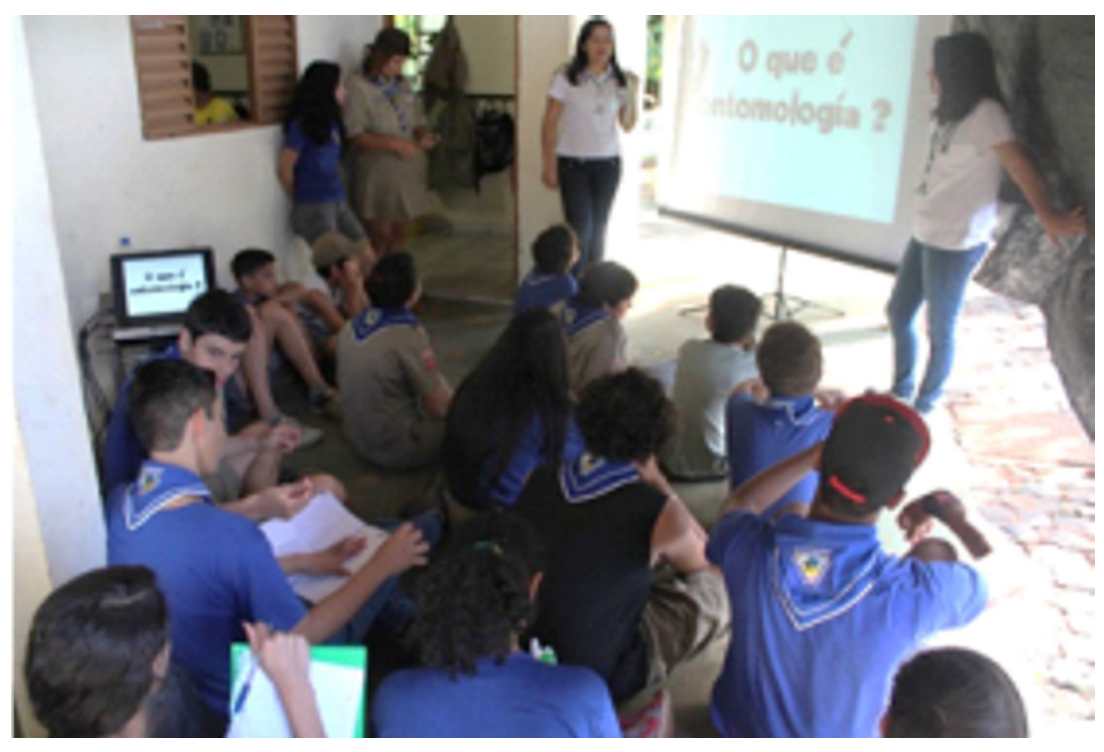

Fonte: Arquivo do PET/Biologia (2014). 
O segundo encontro ocorreu no Laboratório de Biologia Animal do Instituto de Biologia (INBIO/UFU), já que para a parte prática foram usadas as coleçôes de insetos que o laboratório possui. Foi desenvolvida uma aula teórico-prática (Figura 2) com enfoque na diversidade morfológica dos insetos, particularmente nas diferentes adaptaçôes relacionadas aos tipos de asas, aparelhos bucais e pernas. Esses atributos foram utilizados para identificação dos animais com o auxílio de chave dicotômica para indivíduos adultos (Anexo II) e estereomicroscópios.

A aula prática sobre características morfológicas teve enfoque nas ordens Coleoptera (besouros), Diptera (moscas e mosquitos), Hymenoptera (formigas, abelhas e vespas), Lepidoptera (borboletas e mariposas) e Odonata (libélulas). Os escoteiros puderam observar e comparar os animais fixados e coletados, visualizando as estruturas e características explicadas na teoria. Entretanto, percebeu-se que os escoteiros tiveram dificuldades em compreender a chave, sendo necessária uma apresentaçáo complementar de cada uma das características possíveis de serem vistas no estereomicroscópio, reforçando o conteúdo teórico.

Figura 2 - Aula teórica expositiva na UFU

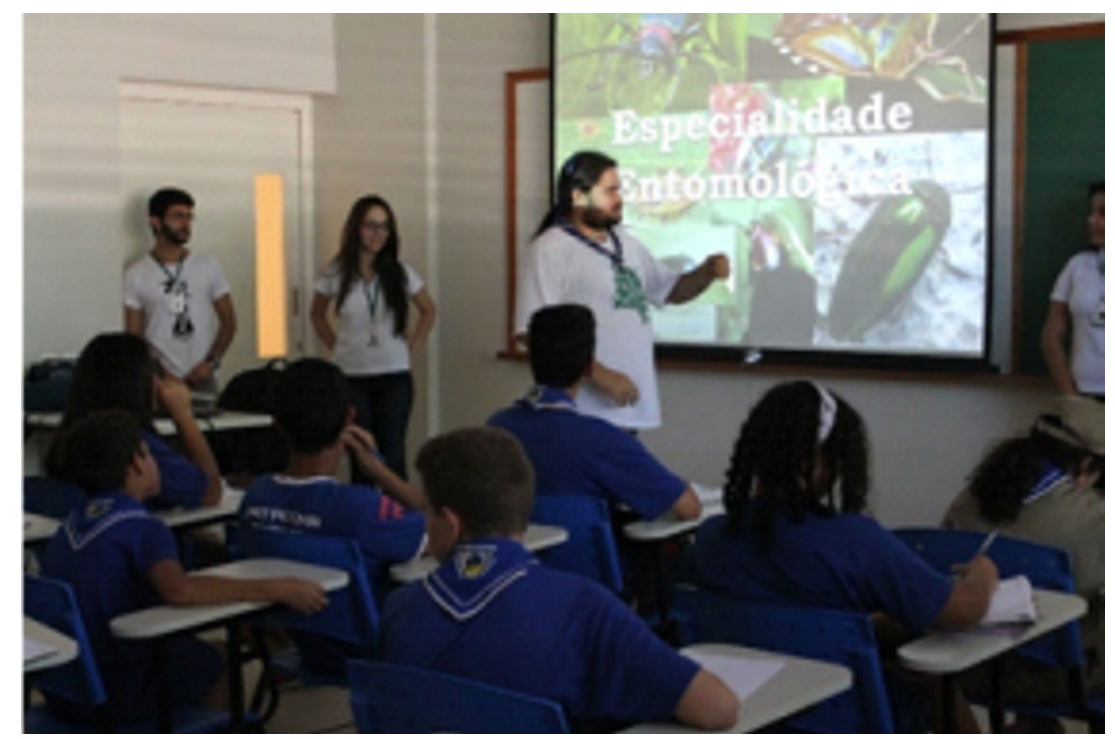

Fonte: Arquivo do PET/Biologia (2014). 
O terceiro encontro também foi realizado na sede dos escoteiros, situada no Parque Municipal do Sabiá. Como forma de inserir os conteúdos trabalhados no cotidiano (Anexo I), os escoteiros foram orientados a elaborar, em grupos, seminários sobre patologias cujos vetores são insetos. Complementarmente, um texto ressaltando a importância dos insetos para o meio ambiente deveria ser elaborado individualmente. Nesse encontro, também foi realizada a dinâmica "Pega o Bicho", em que insetos foram fotografados nas proximidades da sede, a fim de descrevê-los e identificá-los utilizando os atributos abordados no encontro anterior (Figura 3).

Figura 3 - Alunos realizando a dinâmica "Pega o bicho"

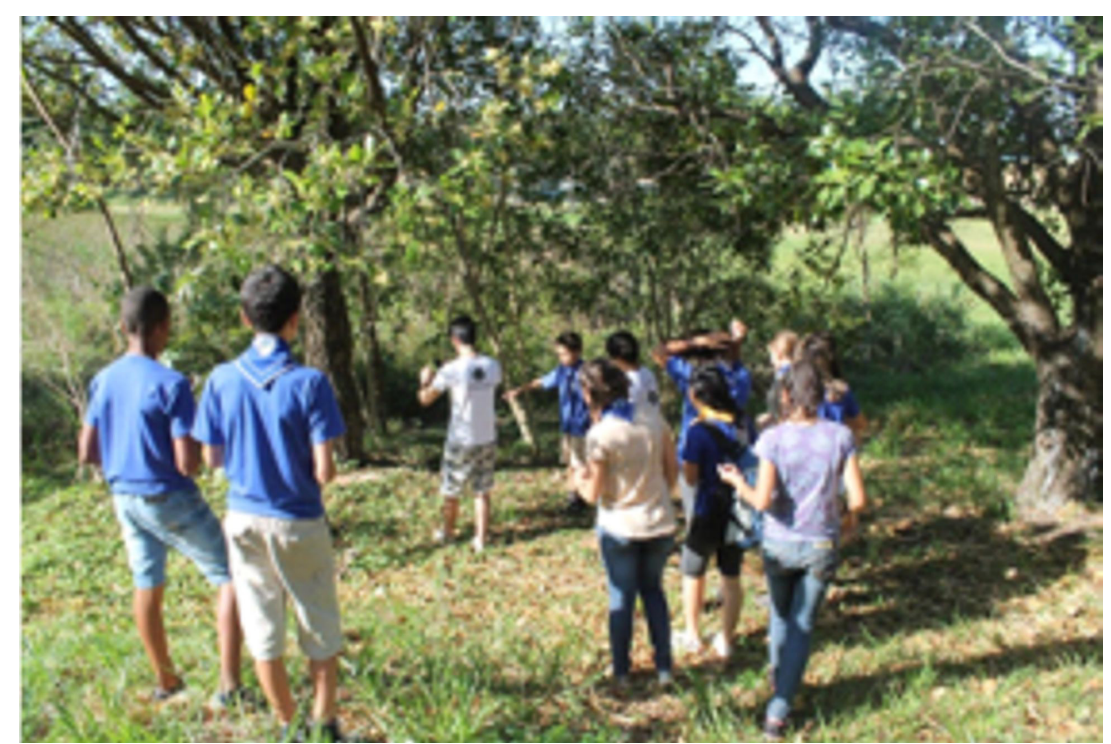

Fonte: Arquivo do PET/Biologia (2014).

No quarto encontro, ocorreu a finalizaçáo do projeto, realizada na sede dos escoteiros, que apresentaram seminários em grupos sobre formas de transmissão e os respectivos vetores das doenças malária, chagas e dengue, utilizando-se cartazes e textos produzidos sobre as temáticas. 


\section{RESULTADOS E DISCUSSÃO}

Ocorreram adaptaçóes da proposta ao longo do desenvolvimento do projeto devido à falta de conhecimento sobre o espaço onde a atividade foi desenvolvida, bem como da diversidade de faixa etária do públicoalvo. $\mathrm{O}$ uso da chave dicotômica foi um recurso desafiador, tanto para os monitores quanto para os alunos, sendo complementado com explicaçóes focadas no aspecto visual da morfologia dos exemplares e com a ajuda do orientador da atividade.

Essa atividade foi inédita e enriquecedora para o PET Biologia, pelo fato do grupo que constituiu o público-alvo já possuir estrutura e dinâmica interna peculiares, ou seja, suas características próprias foram distintas daqueles com as quais, geralmente, o grupo PET se depara em açóes com graduandos e públicos escolares. A extensão é, indubitavelmente, o pilar que pratica ativamente o retorno direto do investimento, feito por meio de tributos, à comunidade externa. Esse retorno foi claramente perceptível ao longo dos encontros, pois os escoteiros mostraram grande envolvimento nas atividades propostas, levantando questionamentos, sendo proativos nas atividades práticas e mantendo bom relacionamento com os membros do PET.

À medida que a atividade foi concebida, desde o planejamento até a discussáo de seus resultados, ocorreu um processo de autoavaliaçáo constante, no que concerne às responsabilidades de cada membro. Nesse sentido, o preparo de materiais, a capacitação dos membros e a execuçáo possibilitaram a deteçáa de pontos de melhoria, que eram discutidos e reavaliados para que os ajustes fossem feitos durante a continuidade da atividade. Também, nos momentos de exposiçáo ou realização das práticas programadas foi observado como o públicoalvo recebia e respondia aos estímulos causados pelas tarefas, a fim de entender e buscar o cumprimento dos objetivos do trabalho. A fluidez da atividade foi ditada pelo ritmo de conduçáo dos membros do PET/Biologia e de sua reação diante dos desafios, da capacidade de adaptação às circunstâncias, da postura adotada ao estar na posição de monitor e profissional em formação. 


\section{CONSIDERAÇÕES FINAIS}

A busca por atividades que aproximem as diferentes esferas - público externo e comunidade acadêmica - auxilia a explorar um dos pilares do ensino superior - a extensão -, colaborando para a formaçáo cidadá dos participantes por meio de experiências didáticas enriquecedoras. Atividades desse cunho propiciam momentos de construçáo e melhoramento contínuos da postura e desenvoltura dos membros do PET/Biologia frente às situaçóes em que precisam transpor o conteúdo aprendido na academia para o público externo, adequando a linguagem, além de planejar e cumprir um cronograma de trabalho.

\section{REFERÊNCIAS}

BRAGA, P. E. T.; ARAÚJO, A. C. M.; CID, M. P. C. O ensino dos insetos na perspectiva de docentes brasileiros e portugueses. Essentia, Sobral, v. 13, n. 2, p. 95-113, 2012.

ESCOTEIROS DO BRASIL. Entomologia. 2017. Disponível em: $<$ http://www.escoteiros.org.br/especialidades/>. Acesso em: 26 abr. 2018.

FERREIRA, V. R. F.; DEUS, T. C.; SOARES, M. H. F. B. O movimento escoteiro como método de educação não formal para a discussão de conceitos químicos. In: ENCONTRO NACIONAL DE PESQUISA EM EDUCAÇÃO EM CIÊNCIAS, 10., 2015, Águas de Lindóia. Anais... Águas de Lindóia: [s.n.], 2015.

FORPROEX - FÓRUM DE PRÓ-REITORES DE EXTENSÃO DAS UNIVERSIDADES PÚBLICAS BRASILEIRAS. Política Nacional de Extensão Universitária. Manaus: FORPROEX, 2012. Disponível em: <http://www.utfpr.edu.br/estrutura-universitaria/ pro-reitorias/prorec/diretoria-de-extensao/documentos-da-extensaode-ambito-nacional/politica-nacional-de-extensao-universitariaforproex-2012/at_download/file>. Acesso em: 4 maio 2018.

GOHN, M. G. Educaçáo não formal na pedagogia social. In: CONGRESSO INTERNACIONAL DE PEDAGOGIA SOCIAL, 1., 2006. Disponível em: <http://www.proceedings.scielo.br/scielo. 
php?script=sci_arttext\&pid=MSC0000000092006000100034\&lng $=e n \& n r m=a b n>$. Acesso em: 6 maio de 2018 .

KRASILCHIK, M. Prática de ensino de biologia. São Paulo: EdUSP, 2008. $197 \mathrm{p}$.

MENDONÇA, S. G. L.; SILVA, P. S. Extensão universitária: uma nova relação com a administração pública. In: CALDERÓN, A. I.; SAMPAIO, H. Extensáo universitária: ação comunitária em universidades brasileiras. São Paulo: Olho d'água, 2002. p. 29-44.

NASCIMENTO, A. O. Educação e civismo: movimento escoteiro em Minas Gerais (1926-1930). Revista brasileira de história da educação, São Paulo, n. 7, jan./jun. 2004.

NUNES, J. R. F.; FREITAS, S. S. S.; GRAÇA, R. F. O escotismo e as práticas escolares no Brasil. In: ENCONTRO DE FORMAÇÃO DE PROFESSORES EM SERGIPE, 4., 2011, Aracaju. Anais... Aracaju: UNIT, 2011. p. 1-15.

PEREIRA, A. P. C. Educaçáo náo formal tendo como exemplo de modelo pedagógico o método escoteiro. 2004. 57 f. Monografia (Graduação em Pedagogia) - Centro Universitário da Cidade do Rio de Janeiro, 2004.

RAFAEL, J. A. et al. Insetos do Brasil: diversidade e taxonomia. Ribeirão Preto: Holos 2012. 795 p.

SOUZA, B. de. Chaves para algumas ordens de insecta. 2007. Disponível em: <http://www.den.ufla.br/attachments/article/70/ apostila_GET101_completa.pdf>. Acesso em: 6 ago. 2018.

UFU - UNIVERSIDADE FEDERAL DE UBERLÂNDIA. Manual de regulamentaçáo dos grupos PET MEC e PET Institucional. Uberlândia: EDUFU, 2015. Disponível em: <http://www.petbio. ib.ufu.br/sites/petbio.ib.ufu.br/files/Anexos/Bookpage/MANUAL UFU PET 2014.pdf>. Acesso em: 26 abr. 2018.

Submetido em 20 de maio de 2018.

Aprovado em 6 de agosto de 2018. 


\section{ANEXO I ESPECIALIDADE ENTOMOLOGIA}

1. Diferenciar insetos, aranhas e escorpióes;

2. Caracterizar os tipos de aparelhos bucais dos insetos, sabendo o tipo de alimentação realizado por cada tipo;

3. Caracterizar os tipos de pernas dos insetos, sabendo o habitat para cada tipo;

4. Caracterizar os tipos de asas dos insetos, sabendo diferenciá-las;

5. Diferenciar cinco insetos de Ordens diferentes;

6. Realizar em sua patrulha ou seção uma apresentação sobre os primeiros socorros a serem feitos em caso de picadas ou queimaduras causadas por insetos;

7. Elaborar um texto explicando a importância dos insetos para o meio ambiente, falando sobre os insetos nocivos e úteis ao homem;

8. Caracterizar formigas, baratas, besouros, gafanhotos, percevejos e moscas quanto a Ordem, tipo de asa, tipo de pernas e aparelho bucal;

9. Realizar em sua seção uma apresentação sobre as doenças causadas por insetos, falando sobre os vetores, sintomas, formas de contágio e meios de prevenção (ESCOTEIROS DO BRASIL, 2017). 
ANEXO II

CHAVE PARA ALGUMAS ORDENS DE INSECTA (ADULTOS

Aparelho bucal sugador labial (Fig. 1) ........................................... 2

1'. Aparelho bucal de outro tipo ...................................................... 4

2(1). Asas posteriores do tipo balancins (moscas, mosquitos, pernilongos, mutucas etc.) (Fig.2).......................DIPTERA

2'. Asas posteriores de outro tipo ou asas ausentes ........................ 3

3(2'). Asas franjadas (tripes) (Fig. 3) ...................THYSANOPTERA 3'. Asas anteriores do tipo hemiélitro (percevejos, Fig. 4; barbeiros, marias fedidas, baratas-d'água, etc.) ou membranosa (pulgóes, cigarras, moscas brancas, Fig. 5) ou tégmina (cigarrinhas, Fig. 6) ou asas ausentes (pulgôes, Fig. 7; cochonilhas, Fig. 8) ..........HEMIPTERA

4(1'). Pernas posteriores saltatórias (gafanhotos, grilos, esperanças, paquinhas, taquarinhas, etc.) (Fig. 9) .................... RTHOPTERA 4'. Pernas posteriores de outro tipo ............................................... 5

5(4'). Asas anteriores do tipo tégmina ................................................ 6 5'. Asas anteriores de outro tipo ou asas ausentes ............................ 7

6(5). Pernas anteriores ambulatórias (baratas) (Fig. 10) ...BLATTODEA 6'. Pernas anteriores raptatórias (louva-a-deus) (Fig. 11) ..MANTODEA

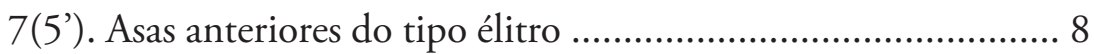

7’. Asas anteriores membranosas ou asas ausentes .............................. 9

8(7). Cercos presentes (tesourinhas) (Fig. 12) .......DERMAPTERA 8'. Cercos ausentes (besouros, joaninhas, serra-paus, vagalumes, pirilampos etc.) (Fig. 13) .............................................. OLEOPTERA

9(7'). Asas com escamas (borboletas e mariposas) (Fig. 14)............ .LEPIDOPTERA

9'. Asas sem escamas ou asas ausentes .......................................10

10(9'). Antenas moniliformes (cupins, siri-siris etc.) (Fig. 15) ......... ISOPTERA

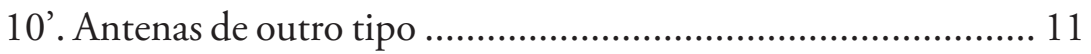

11(10’). Antenas curtas (libélulas) (Fig. 16) ................. ODONATA 
11'. Antenas longas, bem visíveis

12(11'). Asas com aspecto reticulado devido a numerosas nervuras longitudinais e transversais; antenas filiformes ou clavadas (Fig. 17) NEUROPTERA 12'. Asas com poucas nervuras, nunca com aspecto reticulado ou asas ausentes; antenas geniculadas (abelhas, mamangavas, formigas, vespas), setáceas e filiformes (Fig. 18).

HYMENOPTERA
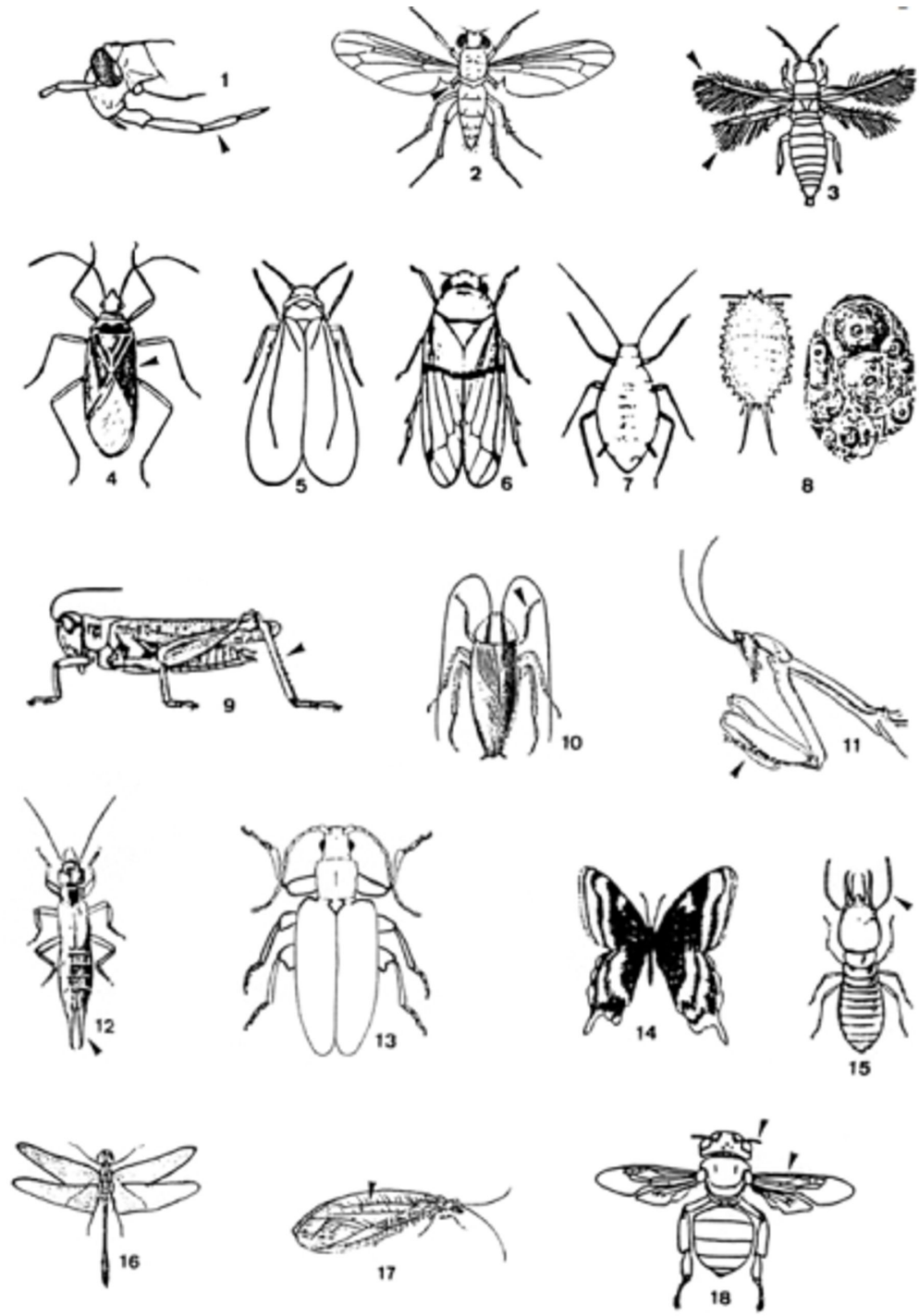

Fonte: SOUZA, B. de (2007). 